\title{
Regarding the article "Irrational fixed dose combinations in Nepal: Need for intervention" (KUMJ, Vol 6, No. 3, Issue 23, p. 399-405)
}

\author{
Poudel $\mathbf{A}^{1}$, Khanal $\mathbf{S}^{2}$, Alam K3 , Palaian $\mathbf{S}^{4}$, \\ ${ }^{1,2}$ Hospital and Clinical Pharmacist, Department of Hospital and Clinical Pharmacy, Manipal Teaching Hospital, \\ ${ }^{3}$ Lecturer, ${ }^{4}$ Assistant Professor, Department of Hospital and Clinical Pharmacy/Pharmacology, Manipal Teaching \\ Hospital/ Manipal College of Medical Sciences
}

\section{Dear Editor,}

In the last issue of the KUMJ we reviewed the availability of irrational fixed dose combinations (IFDCs) in Nepal ${ }^{1}$. At this point, we would like to mention the findings from a market survey conducted by us in six major cities of Nepal on the availability of IFDCs. The survey was conducted in Pokhara, Bhairahawa, Nepalgunj, Birgunj, Biratnagar and the capital city, Kathmandu. The Pharmacists from Manipal Teaching Hospital, Pokhara visited these six cities and gathered information on the availability of the IFDCs in the respective cities. We also purchased few irrational combinations available in the market. Some combinations which are included in drug list but still considered irrational were also purchased. The details regarding some of the IFDCs that are identified by us are listed below.

1. Tab. Furazolidone $100 \mathrm{mg}+$ Metronidazole $300 \mathrm{mg}$ : Though claimed to be broad spectrum, combining antiamoebic with antibacterial is irrational because patient suffers from only one type of diarrhea. Using the combination leads to adverse effects, increases cost and encourages resistance ${ }^{2}$. Though this product is available; it is not registered in Nepal by the Department of Drug Administration (DDA) - the national drug regulatory body of Nepal.

2. Tab. Diphenoxylate $2.5 \mathrm{mg}+$ Atropine Sulphate $0.025 \mathrm{mg}+$ Furazolidone $50 \mathrm{mg}$ : Combination of antimotility drugs with antiamoebic drugs cannot be justified. Furazolidone has been banned in several countries as it was shown to have carcinogenic potential following long-term administration to experimental animals ${ }^{3}$. This product is also not registered by the DDA.

3. Cap. Ampicillin $250 \mathrm{mg}+$ Cloxacillin $250 \mathrm{mg}$ : Both of the antibiotics belong to same class namely penicillins acting at the same site by same mechanism offering no synergism ${ }^{1}$. Similarly, ampicillin is inactive against Staphylococcus and cloxacillin is inactive against Streptococci. Since the amount of drug which is actually going to act in any individual patient is halved, efficacy is reduced and chances of selecting resistant strains is increased. For any given infection, one of the components is useless but adds to cost and adverse effects ${ }^{2}$. This product is registered by the DDA.

Beyond these there were other IFDCs like Tab. Ofloxacin $200 \mathrm{mg}+$ Tinidazole $600 \mathrm{mg}$, Susp. Ciprofloxacin $125 \mathrm{mg}+$ Metronidazole Benzoate $100 \mathrm{mg}$, Susp. Norfloxacin $100 \mathrm{mg}$ + Ornidazole $200 \mathrm{mg}$, Susp. Ofloxacin $50 \mathrm{mg}+$ Tinidazole $150 \mathrm{mg}$, Tab. Tinidazole $600 \mathrm{mg}+$ Ciprofloxacin $500 \mathrm{mg}$ etc which are not approved by any standard drug information sources but are available in Nepalese market. It is surprising to know that most of these combinations are not registered in DDA but are still available in the market.

Our preliminary findings suggest the need for immediate regulatory measures to contain the availability of IFDCs in Nepal. We also recommend the need for extensive research in this area. The responsibility also lies in the hand of prescribers and pharmacist who prescribe and market these drugs. There is also need for adequate awareness program for the consumers to be aware of these IFDCs.

\section{Acknowledgements}

The authors acknowledge the Health Action International - Asia Pacific (HAI-AP) for funding us in carrying out the market survey. We also acknowledge Ms. Jinani Jayasekara, project officer of HAIAP for reviewing the initial version of the manuscript and suggesting modifications. 


\section{References}

1. Poudel A, Palaian S, Shankar PR, Jayasekera J, Izham MIM. Irrational fixed dose combinations in Nepal: Need for intervention. Kathmandu Univ Med J. 2008; 6:1-5.

2. Gautam CS, Aditya S. Irrational drug combinations: Need to sensitize undergraduates. Indian J Pharmacol 2006; 38:169-70.
3. Department of Economics and Social Affairs. UN Consolidated List of Products Whose Consumption and/or Sale Have been Banned, Withdrawn, Severely Restricted or NotApproved by Governments (Eighth Issue, Pharmaceuticals, 2003). United Nations Headquarters, New York: United Nations Publication; 2003. 